\title{
PERCEPÇÃO DO RACISMO ESTRUTURAL NO ACESSO AO SERVIÇO PÚBLICO DE ABASTECIMENTO DE ÁGUA NO BAIRRO NEGRO RUA NOVA, EM FEIRA DE SANTANA- BAHIA
}

\author{
PERCEPTION OF STRUCTURAL RACISM IN ACCESS TO PUBLIC WATER SUPPLY IN THE \\ RUA NOVA BLACK NEIGHBOURHOOD, IN FEIRA DE SANTANA - BAHIA.
}

\author{
Thiago Assunção dos Santos ${ }^{a}$, Luiz Roberto Santos Moraes ${ }^{a}$, Cristina Larrea-Killinger ${ }^{b}$ \\ a Universidade Federal da Bahia, ' Universitat de Barcelona
}

thiago.ambientalista@gmail.com, moraes@ufba.br, clarreakillinger@gmail.com

Submissão: 16 de junho de 2021 Aceitação: 19 de novembro de 2021

\section{Resumo}

Este estudo tem como objetivo avaliar a percepção da população do bairro Rua Nova a respeito da qualidade da prestação do serviço público de abastecimento de água sob a ótica do racismo estrutural. Para tanto, foi utilizada metodologia qualitativa buscando maior rigor técnico e empírico, e dentro dessa abordagem a Observação Participante como técnica de pesquisa, tendo-se recorrido aos instrumentos entrevista semiestruturada e dados secundários do IBGE. Como resultado, o bairro Rua Nova apresenta uma população de rendimento mensal baixo, com sua maioria percebendo até 2 salários-mínimos, e majoritariamente classificados pelo IBGE como de cor/raça negra. Os componentes do saneamento básico pesquisados estão praticamente universalizados em termos de cobertura, o abastecimento de água com $96,99 \%$ e esgotamento sanitário com $95,27 \%$. Entretanto, a percepção dos moradores do bairro negro Rua Nova quanto à qualidade do serviço público prestado pela concessionária estadual foi central nessa pesquisa tendo se revelado desigual, por privar a população do direito à água com regularidade e quantidade suficiente, colocando em risco a saúde dessas pessoas. Tal ato é compreendido como discriminatório à população negra submetida ao racismo estrutural.

Palavras-chaves: abastecimento de água; racismo estrutural; bairro negro.

\section{Abstract}

This study aims to evaluate the perception of the population of the Rua Nova neighborhood regarding the quality of the public water supply service under the perspective of structural racism. For that, qualitative methodology was used seeking greater technical and empirical rigor, and within this approach Participant Observation as a research technique, using semi-structured interview instruments and secondary data from IBGE. As a result, the Rua Nova neighborhood has a low monthly income population, with most of them earning up to 2 minimum wages, and mostly black people. The basic sanitation components surveyed are practically universal, the water supply with $96.99 \%$ and sewage with $95.27 \%$. However, the perception of the residents of the black neighborhood of Rua Nova regarding the quality of the public service provided by the state concessionaire was central to this research, which proved to be unequal, as it deprives the population of the right to water with regularity and sufficient quantity, putting their health at risk. Such an act is understood as discriminatory against the black population subjected to structural racism.

Keywords: water supply; structural racism; black neighborhood. 


\section{INTRODUÇÃO}

No Brasil, os serviços públicos de abastecimento de água e de esgotamento sanitário são prestados por autarquias, departamento e empresas municipais, empresas privadas e a grande maioria pelas Companhias Estaduais de Água e Esgoto. São empresas estatais, que, por meio de delegação municipal, têm a responsabilidade pela prestação destes serviços, efetuando a construção, a operação, a manutenção e ampliação de sistemas que atendam principalmente às populações urbanas.

Na Bahia, a Empresa Baiana de Águas e Saneamento S/A (EMBASA), é responsável pela prestação dos serviços públicos de água e esgoto de 368 municípios, dentre eles Feira de Santana, em cuja sede municipal onde está localizado o bairro negro Rua Nova, lócus dessa pesquisa.

Segundo Sistema Nacional de Informação sobre Saneamento (SNIS), nesse município, o atendimento em abastecimento de água da população urbana em 2019 era de 100\% (IN023) e em esgotamento sanitário de 74,64\% (IN015) (BRASIL, 2020). Logo, tem-se um serviço público que garante o acesso à água para consumo humano à toda a população urbana, sendo com isso alcançado o princípio fundamental da Lei Nacional de Saneamento Básico, Lei n. 11.445/2007, da universalização de acesso (art. $2^{\circ}$ ), da prestação dos serviços públicos (BRASIL, 2007).

No caso do Brasil, o principal instrumento visando o planejamento para a referida universalização, é representado pelo Plano Nacional de Saneamento Básico (Plansab) (ALEIXO et al., 2016). O Plansab, estabelecido na Lei n. 11.445/2007, pauta-se em uma visão estratégica para o futuro e parte do princípio de que os avanços ocorridos nas últimas décadas em termos de acesso deram-se de forma a consolidar as desigualdades, estando o déficit concentrado em grupos com características comuns, famílias com vulnerabilidade econômica, residentes prioritariamente nas macrorregiões Norte e Nordeste do País, sobretudo em áreas de periferias urbanas e em áreas rurais (BRASIL, 2007; 2019).

Tal desigualdade é demonstrada em estudos desenvolvidos em cidades brasileiras como: São Luís-MA; Marau-RS; e Salvador-BA, respectivamente (PEREIRA; JUNIOR; RODRIGUEZ, 2013; MACIEL et al., 2013; BORJA et al., 2015; BORJA; MORAES; BOTEON, 2021).

Apesar do reconhecimento das desigualdades de acesso ao saneamento básico no Brasil, poucos estudos buscam aprofundar no quesito étnico-racial. A sociedade brasileira, ainda é sustentada em forte preconceito de classe, de raça e de gênero, por uma estrutura social marcada por alta concentração de riqueza e poder, aliado a processos de exclusão e desigualdade. O fenômeno da desigualdade se manifesta pela lógica do capitalismo, sendo que nas cidades existem os espaços segregados, com marcas de uma estrutura social entre incluídos e excluídos que separa indivíduos pela renda, níveis de escolaridade, acesso à serviços públicos, cultura, educação, sobretudo pela raça (BORJA et al., 2015; SANTOS et al., 2021).

A histórica invisibilidade dos bairros negros para o acesso às políticas públicas, é um exemplo disso, com provável diferenciação na prestação pela Embasa de serviços públicos de abastecimento de água e de esgotamento sanitário nestes bairros, uma vez que as populações negras se mantêm forte relação com a questão da renda, porque na historiografia brasileira a população pobre é negra, e isso está condicionada à exploração da força de trabalho, baixos salários, mas, sobretudo com a expulsão dessa população dos centros urbanos para locais periféricos, como modo de "higienizar" a cidade mascarando a ideologia de eugenia. Tal probabilidade revela a violação não só de um dos princípios fundamentais da Lei $n$. $11.445 / 2007$, como também dos que estão no art. 5ำ da Constituição Federal de 1988, como a cidadania e a dignidade da pessoa humana (BRASIL, 1988; 2007).

Feira de Santana, cidade localizada no estado da Bahia, inscreve-se nessa dinâmica de exclusão e desigualdade sociorracial, onde os detentores do poder são contemplados com melhores oportunidades, e as populações de baixa renda são alijadas dos seus direitos fundamentais. A Rua Nova, bairro com maioria de pessoas negras da cidade de Feira de Santana, pode ser um exemplo desse fenômeno. 
No que tange a estas condições de acesso ao saneamento básico, a população afrodescendente está submetida às consequências dramáticas da desigualdade racial, tendo de conviver com uma série de privações, como de não ter acesso a educação de qualidade, a moradia com condições sanitárias adequadas, a sistema 'de transporte público de qualidade, além de residir em ambientes insalubres, comprometendo a saúde física e mental, o que pode levar a quadros graves de morbidade e mortalidade.

Com isso, esse artigo se justifica visando contribuir no combate ao racismo estrutural (ALMEIDA, 2018) existente nas instituições públicas que incide sobre a população negra no acesso aos serviços públicos de abastecimento de água e esgotamento sanitário, e para a formulação e implementação de políticas públicas direcionadas a esse grupo social, com o objetivo de contribuir para a melhoria de sua condição de vida e a redução das iniquidades, como também contribuir com a produção científica trazendo para o debate um tema relevante e sobretudo urgente, que é discutir saneamento na perspectiva de raça e do racismo.

Ademais, se faz necessário e relevante o debate sobre 0 acesso à água $e$ ao esgotamento sanitário como direito humano na perspectiva das relações étnico-raciais, sobretudo contribuir com publicações científicas no âmbito de um novo olhar para a área sanitária e ambiental a respeito das populações negras. Assim, este estudo tem como objetivo avaliar as percepções da população do bairro Rua Nova a respeito da qualidade do serviço público prestado de abastecimento de água sob a ótica do racismo estrutural.

\section{Racismo Estrutural na perspectiva do saneamento básico}

Desde o período escravocrata, assim como, após abolição da escravatura, as populações negras são negligenciadas às políticas públicas de saneamento básico. Historicamente, os negros escravizados no período colonial, eram conhecidos por "tigres", devido às manchas em seus corpos de resíduos de excrementos humanos ressecados na pele. Eles eram postos na condição de subserviência pela classe dominante, tendo a tarefa de realizar o esvaziamento dos potes com excretas humanos e ainda abastecer com água para consumo e uso diário na casa grande, sobrados e repartições públicas, isto é: os corpos negros eram os próprios "sistemas" de água e esgoto da cidade (REZENDE; HELLER, 2008; JESUS, 2020).

No Brasil, a partir da Lei Áurea, de maio de 1888 , a população negra foi deixada nas ruas e jogada à própria sorte, sem nenhum amparo do Estado brasileiro e de seus governantes. Nesse sentido, as considerações de Maricato (1995, p. 18) fundamentam a consideração supracitada ao relatar:

O aparato legal urbano, fundiário e imobiliário, que se desenvolveu na segunda metade do século XIX, forneceu base para o mercado imobiliário fundado nas relações capitalistas e também para a exclusão territorial. Os Códigos de Posturas Municipais de São Paulo (1886) e Rio de Janeiro (1889) proibiram a construção de cortiços ou 'edificações acanhadas' nas áreas mais centrais.

Isso quer dizer que o Estado brasileiro almejava modelos de urbanização desenvolvido na Europa e, dessa forma, implementou a higienização dos grandes centros urbanos, o que culminou na expulsão da população negra para as áreas periféricas das cidades, em cortiços, casebres e barracões onde também se concentravam operários e pessoas pobres (VALADARES, 2000; MARQUES, 1995).

Tecer um olhar crítico sobre a higienização das cidades permite identificar a violência sofrida pelos povos negros. A higienização como prevenção às doenças mascarava a ideologia da eugenia, ou seja, as cidades deveriam ser limpas racialmente, como destacou Lira (1999, p. 51): "um meio urbano visto como degenerador de uma cidade asséptica, civilizada e domesticada para as funções do trabalho, mas também 'eugênica', quer dizer, racialmente higienizada".

Ainda no campo da eugenia racial, Lira (1999) traz em sua produção textual a fala de um engenheiro sanitarista, em 1920, na cidade de Recife, para o qual a higiene e eugenia "são duas ciências que precisam caminhar emparelhadas, uma complementar da outra (...) a primeira cuida da cidade, e a segunda 
aperfeiçoa a raça de cuja perfeição e vitalidade muito depende o progresso do País" (PEREIRA, 1928, p.72 apud LIRA, 1999, p. 54). Soma-se a essa visão e decisões políticas, a definição do governo brasileiro em intensificar a miscigenação do povo brasileiro por meio das ações que estimularam a imigração de milhares de famílias europeias para assumir postos de trabalho em indústrias, cidades e no espaço rural.

Diante desse contexto, é importante que na constituição identitária do profissional da área de Engenharia Sanitária e Ambiental, dentre tantas responsabilidades, o maior cuidado no trato com as demandas das populações negras. Não se pode negligenciar o impacto dos mais de 300 anos de escravidão e, por conseguinte, as severas imposições políticas segregacionistas alvejando as pessoas negras no Brasil. Portanto, discutir o direito humano essencial de acesso igualitário aos serviços públicos de saneamento básico, dentre eles os de abastecimento de água e de esgotamento sanitário, perpassa por uma preocupação, não apenas econômica, mas, sobretudo, racial para alcançar a real necessidade dos afrodescendentes.

Todo esse contexto apresentado se mostra de suma importância nesta produção textual por ser a soma de debates científicos que coadunam para a compreensão do Racismo Estrutural, largamente naturalizado nas relações sociais e que repercute com muita intensidade nas políticas públicas.

O filósofo Sílvio Almeida (2018) que em sua obra "O que é racismo estrutural?" leva o leitor a ampliar os olhares não somente para as questões repercutidas no cotidiano, mas sobretudo, verificar como surgiu e de que forma - legado histórico recebe espaço para continuar a existir:

O racismo não é um ato ou um conjunto de atos e tampouco se resume a um fenômeno restrito às práticas institucionais; é, sobretudo, um processo histórico e político em que as condições de subalternidade ou de privilégio de sujeitos racializados é estruturalmente reproduzida (ALMEIDA, 2018, p.29).

Se ater a colocação de Almeida (2018) sobre o Racismo Estrutural e trazê-la para o campo do saneamento básico representa uma ação de tensionamento sobre como a estrutura e determinações das engenharias pensam e refletem sobre a racialização da estrutura social brasileira. Assim, o cenário do acesso ao saneamento básico reforça o entendimento de que as políticas públicas da área têm seguido à lógica estruturalmente reproduzida, a qual repercute as ações do racismo ao legitimar a "falta de regularização no acesso das famílias a infraestrutura sanitária" (GOMES; HELLER, 2009, p.2).

Para compreender com dados essas inquietações, aqueles apresentados pelo Ipea (2015), revelam um aumento expressivo de domicílios com abastecimento de água, sobretudo, casas com chefias por pessoas negras, pois em 1995, apenas $76,6 \%$ destes domicílios chefiados por pessoas negras contavam com abastecimento de água adequado, em 2015 chega a $91,8 \%$. Mesmo com aumento significativo na cobertura do serviço às populações negras, o próprio Ipea mostra que o benefício ocorrido às famílias negras "não se equipara ao serviço prestado à população branca", que em 2015 atingiu $95,4 \%$, isso sem avaliar a qualidade do serviço prestado. Quando o assunto é esgotamento sanitário o percentual de cobertura por esse serviço é menor entre as populações brancas e negras. Portanto, em 2015 a população branca contava com $81,7 \%$ de seus domicílios com alguma solução para os esgotos sanitários, enquanto esse percentual atingia $68,8 \%$ da população negra.

Exemplo disso se dá a partir da falta de saneamento básico para as populações que resistem no bairro negro, no subúrbio, no gueto, nos assentamentos, nos quilombos, nas aldeias indígenas, porque estar nesses locais foge à norma e ao padrão estabelecido pelo grupo hegemônico, logo são forjadas circunstâncias que dificultam 0 acesso ao direito fundamental das pessoas ao abastecimento de água e ao esgotamento sanitário, sendo que na ausência desses direitos as populações estão condicionadas à contrair Doenças Relacionadas ao Saneamento Ambiental Inadequado (DRSAl) que podem levá-las até à morte.

Para Foucault (2005, p. 309) "o racismo é uma tecnologia do poder". Isto é, o saneamento básico, a saúde pública, a segurança, são exemplos do exercício que o poder estatal tem 
sobre a manutenção da vida da população, sendo que a ausência destes seria o deixar morrer pelo Estado. Foucault denomina de biopoder esse exercício do poder sobre a vida que tem 0 racismo como mecanismo fundamental do poder do Estado (ALMEIDA, 2018).

Portanto, verifica-se que a concepção institucional do racismo trata o poder como elemento central da relação racial, com isso, racismo é dominação. "No caso do racismo institucional, o domínio se dá com estabelecimento de parâmetros discriminatórios baseados na raça, que são determinantes para manter a hegemonia do grupo racial no poder" (ALMEIDA, 2018, p.31). $O$ racismo tem permitido cada vez mais a naturalização da morte pela violência a qual populações inteiras estão submetidas, seja pela perda de crianças por "balas perdidas" ou pela convivência em área inteiras sem ou com saneamento básico deficiente, sem serviços públicos de saúde e de educação, sendo que esse comportamento se traduz no genocídio dos corpos negros.

Dessa forma, pode se perceber que apesar do Brasil ter avançado nas implementações de ações e políticas afirmativas para reverter estas desigualdades sociorraciais nas mais diversas instâncias estatais e do campo social, essa negligência do poder público com o bairro negro pode ser compreendida sob uma perspectiva de Racismo Estrutural (BAEZ, 2017). Assim, repensar o serviço público de saneamento básico prestado na perspectiva das relações étnico-raciais torna-se uma necessidade, de forma a reparar os impactos negativos do Racismo Estrutural.

\section{METODOLOGIA}

Entende-se que a pesquisa qualitativa é uma opção coerente para acessar à observação das dimensões territoriais como o bairro Rua Nova, ao percorrer vias, ruas, becos e avenidas. É a partir disso, que a observação das condições e práticas por parte do envolvimento do pesquisador no cotidiano das pessoas constitui um método de coleta de dados de longa tradição nas ciências sociais e aplicado para o estudo de avaliação das infraestruturas (LARREA et al., 2013)
Com isso, considerando que toda pesquisa qualitativa parte de uma experiência, como define Minayo (2012), as características próprias da pesquisa qualitativa pressupõem o envolvimento do pesquisador com as narrativas dos sujeitos que contribuem com os dados da investigação. A pesquisa qualitativa inclui a Observação Participante que integra de modo sistêmico, a partir da experiência, a observação das práticas e a escuta de conversas e aplicação de entrevistas. Sobre isso, Minayo aponta que uma pesquisa qualitativa busca compreender as experiências das pessoas sobre a sua relação com o mundo que ajuda a construir, bem como suas vivências com os fenômenos sociais que atravessam seus cotidianos:

[...] trabalha com o universo de significados, motivações, crenças, valores e atitudes, o que corresponde a um espaço mais profundo de relações, dos processos e dos fenômenos que não podem ser reduzidos à operacionalização (MINAYO, 2004, p. 21-22).

Então, no âmbito do campo das abordagens qualitativas, escolheu-se a Observação Participante como técnica de investigação social, pois esta propicia ao pesquisador dois elementos de suma relevância: compreensão; e interpretação. Sobre compreender, Minayo (2012, p. 623) elucida:

Ao buscar compreender é preciso exercitar também o entendimento das contradições: o ser que compreende, compreende na ação e na linguagem e ambas têm como características serem conflituosas e contraditórias pelos efeitos do poder, das relações sociais de produção, das desigualdades sociais e dos interesses.

É justamente essa característica de acessar os conflitos, as desigualdades sociais, as relações de poder que fortalece a utilização da Observação Participante como um caminho para atender ao objetivo de pesquisa. Nesse sentido, esse estudo procurou investigar a percepção da população no acesso e qualidade do serviço público prestado de abastecimento de água no bairro Rua Nova, em que sua compreensão pauta-se na verificação de que esse serviço público prestado na cidade de 
Feira de Santana se apresenta de modo desigual como pode ser apontado na Observação Participante. Logo, se faz relevante problematizar as particularidades de um bairro negro, periférico, constituído por trabalhadores negros e trabalhadoras negras, abrange uma variedade de fatores próprios das desigualdades sociorraciais típicas do povo brasileiro.

A Observação Participante foi realizada por meio de visitas pelo primeiro autor no período de julho de 2019 a fevereiro de 2020, percorrendo as ruas do bairro, algumas residências familiares, tendo sido acompanhado todas às vezes pela agente comunitária de saúde local e durante a realização das entrevistas. Observar, vivenciar, ter a experiência e diálogo com os participantes desta pesquisa traz para os estudos em relação ao abastecimento de água um repertório que não se restringe à discussões técnicas, meramente positivistas, fechadas em uma área do conhecimento mais enrijecida. Muito pelo contrário, dialogar com os moradores do bairro Rua Nova possibilitou ao pesquisador da Engenharia Ambiental e Sanitária a aproximação para uma compreensão sobre um povo e sua territorialidade, o que incide na interpretação dos dados da pesquisa sob uma ótica outra, a ótica de quem produz e reproduz o Bairro Negro.

O bairro Rua Nova, identificado a partir do conceito utilizado pelo pesquisador Henrique Cunha Júnior $(2007 ; 2017)$ como Bairro Negro, devido a esse território além de ter maior contingente de pessoas afrodescendentes, possuir, em sua construção, um processo histórico de relações sociais, culturais, manifestações religiosas de matriz africana, dentre outros. A área de estudo desta pesquisa está localizada na cidade de Feira de SantanaBahia (Figura 1) em que se apresenta características suficientes para se constituir no lócus da pesquisa, principalmente porque é um bairro majoritariamente negro, culturalmente conhecido pelos grupos de Afoxés que tradicionalmente desfilam na micareta (festa momesca) da Cidade; pela existência dos terreiros das religiões de matriz africana que referência o legado africano; como também por ser parte de processos históricos ocorridos em Feira de Santana.

Figura 1 - Mapa do bairro Rua Nova, Feira de Santana-Bahia.

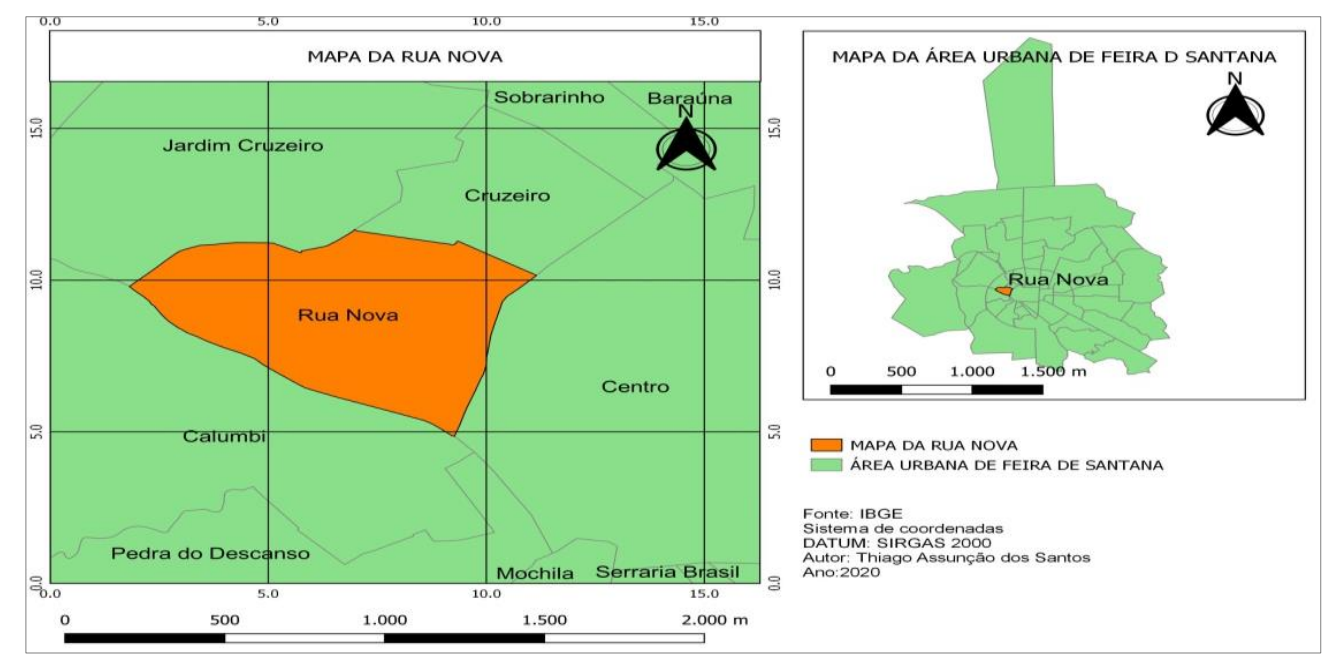

Fonte: elaborada pelo primeiro autor (2020).

Para tanto, foi utilizada na pesquisa qualitativa que deu origem a esse artigo, a entrevista semiestruturada como a mais relevante técnica de coleta de dados. Segundo Minayo (1994), tal instrumento visa buscar individualmente informações que revelem valores culturais, identitários e, também, a obtenção de concepções políticas e relações de poder.

Definida a entrevista semiestruturada como um dos instrumentos de coleta de dados, partiu-se para a definição dos participantes da 
pesquisa, os quais foram selecionados de acordo com o objetivo da pesquisa. Inicialmente, foram selecionados cinco participantes moradores do bairro estudado, entre homens e mulheres, faixas etárias diferentes, e cada um com elementos sociorraciais distintos. O contato inicial do primeiro autor com uma das participantes da entrevista, a agente comunitária de saúde, por indicação de professor da Universidade Estadual de Feira de Santana (UEFS) que já desenvolveu pesquisa nesse mesmo espaço. A agente comunitária de saúde local, moradora do bairro Rua Nova desde sua infância, mulher negra e participante do grupo cultural e Afoxé, sendo que por seu intermédio foi possível conhecer os demais participantes.

Os depoimentos foram significativos para a compreensão dos problemas de abastecimento de água e esgotamento sanitário em pesquisa qualitativa e ocorreram conforme a disponibilidade de cada um dos entrevistados e características seguintes: a) 1 homem e 1 mulher na faixa etária acima de 50 anos, cujo perfil teve como finalidade acessar memórias e narrativas de quem acompanhou de perto os primeiros indícios da urbanização do bairro e das ações para o abastecimento de água e o esgotamento sanitário no bairro da Rua Nova (o Sr. João e Sra. Helena); b) 1 homem e 1 mulher com idade inferior à 50 anos, cujas narrativas dariam conta de expor suas compreensões e interpretações sobre um cenário pós primeiras ações higienistas e sanitárias no referido bairro negro (Sr. José e Sra. Maria). Posteriormente foi incluída mais uma mulher (Sra. Ana), devido a existência de um poço raso no lote de sua residência que, quando necessário, atende aos moradores do bairro, totalizando-se assim cinco entrevistados. Para além das questões relacionadas aos componentes de saneamento básico pesquisados, buscou-se obter respostas relativas à questão identitária pessoal e do bairro no marcador racial.

Os participantes das entrevistas foram relevantes para essa pesquisa qualitativa em face ao conhecimento dos mesmos em relação ao bairro, seja pela vivência desde a infância, prestação de serviço e participação em movimentos e atividades culturais, e isso se deu pelo sistema "bola de neve", em que um participante indica o outro. Visando preservar a identidade dos entrevistados, baseado em questões éticas, utilizou-se nomes fictícios e atividade desenvolvida.

As entrevistas semiestruturadas ocorreram nos meses de novembro de 2019 e janeiro e fevereiro de 2020. A gravação dos diálogos foi feita por meio de aplicativo gravador do smartphone, com transcrição realizada pelo primeiro autor com uso da ferramenta do Microsoft Word. Todas entrevistas realizadas com os cinco moradores do bairro Rua Nova, atenderam a Resolução $n$. 466/2012 do Conselho Nacional de Saúde (BRASIL, 2012) que dispõe sobre diretrizes e normas regulamentadoras de pesquisas envolvendo seres humanos, com utilização de Termo de Consentimento Livre e Esclarecido (TCLE), que incluiu os riscos em participar da pesquisa e a desistência em qualquer momento que o entrevistado desejasse, sendo assinados em duas vias, uma ficando com o entrevistado e a outra com o pesquisador, primeiro autor.

Houve também a coleta de dados secundários do Censo Demográfico 2010 do IBGE, em que se buscaram informações sobre o bairro Rua Nova, no qual foram disponibilizadas pela agência regional do IBGE em Feira de Santana por meio de contato via email pessoal (thiago.ambientalista@gmail.com) e e-mail institucional da gerência (não foi autorizado a descrição) ocorrido em 28 de fevereiro de 2020. As variáveis utilizadas foram: cor/etnia; renda; abastecimento de água; e esgotamento sanitário.

\section{RESULTADOS E DISCUSSÃO}

\section{Característica socioeconômica no bairro Rua Nova}

Conforme já definido no presente estudo, o uso da terminologia negro denominado aqui equivale a pessoas classificadas como pretos e pardos nos Censos do IBGE. De acordo com os dados do IBGE (2010), o bairro Rua Nova revela ser majoritariamente negro, tendo um total de $88,15 \%$ de pessoas negras (somatório de pretos e pardos, autodeclarados quando do Censo realizado pelo IBGE), sendo que a maioria dos participantes da entrevista se autoidentificaram como negros, apenas $\mathrm{Sr}$. João se autodeclarou como homem branco. Com isso, o bairro Rua Nova pode ser 
considerado Bairro Negro, segundo as definições de Cunha Júnior (2007) e Ramos (2013). Mesmo não sendo o bairro mais negro de Feira de Santana, ele se destaca em toda à cidade e até no estado da Bahia como o bairro de maior referência de cultura popular negra, tendo como evidência o tradicional bloco afro Afoxé Pomba de Malê que, desde o seu surgimento, demarcou onde nasceu o grupo, porque o nome faz menção à Dona Pomba e, também, à Revolta dos Malês ${ }^{1}$ (MIRANDA, 2014).

Rua Nova, como todo bairro periférico, foi e ainda é constituído por trabalhadoras e trabalhadores, em sua maioria pessoas negras, em geral, formado por famílias de baixos salários e com participação em algum programa de redistribuição de renda, como o Bolsa Família, por exemplo. Nesse sentido, buscou-se apresentar 0 resultado das condições de renda do bairro Rua Nova por raça/cor a partir de pessoas com 10 anos ou mais de idade conforme apresentado na Tabela 1.

Segundo IBGE (2010), as faixas de rendimento domiciliar mensal de $1 / 2$ a 1 e 1 a 2 salários-mínimos incidem com maior frequência sobre as famílias negras. Vale ressaltar um dado relevante que é o percentual de pessoas negras sem nenhum rendimento atingindo $39,78 \%$, que representa um valor alto e revela o grau de desigualdade da área de estudo. Nesse caso, percebe-se as condições de privações submetidas à população negra, pois o acesso a salários melhores capazes de garantir condições de dignidade é uma condição difícil de ser experimentada na área, indicando o grau de marginalização sob o qual a população está submetida, a qual é a expressão da estrutura social do sistema capitalista e das relações sociais racializadas.

\section{Abastecimento de água no bairro Rua Nova}

Os dados obtidos do Censo Demográfico de 2010 do IBGE disponibilizados via mensagem pessoal pela agência regional de Feria de Santana, apresentam no bairro Rua

${ }^{1}$ Movimento organizado pelos negros mulçumanos que, na madrugado do dia 25 de janeiro de 1835 , saíram pelas ruas do centro de Salvador se unindo a outros grupos para entrar no combate com a força nacional em busca de sua libertação. Mesmo os
Nova uma população recenseada de 13.073 habitantes, por tipo de abastecimento de água em sua residência e que autodeclararam a sua raça/cor. Como apresentado na Tabela 2, quase toda a população do bairro $(96,99 \%)$ encontrava-se atendida pela rede geral de distribuição de água, sem contudo ser informado a qualidade do serviço prestado.

Tal informação traz consigo a noção de que $\mathrm{o}$ bairro tem um serviço público de abastecimento de água praticamente universalizado; porém, sob a ótica do que é abordado por Garcia (2007), de que há desigualdade na prestação desse serviço entre bairros ricos e pobres, esse resultado não traz a garantia que a água é distribuída de forma regular/contínua, nem que a qualidade da água para consumo humano seja potável e segura. Segundo esse pressuposto, mais adiante pode ser verificada a percepção da população quanto às questões relativas ao atendimento do abastecimento de água para as famílias do bairro negro Rua Nova.

\section{Percepção dos moradores entrevitados do bairro Rua Nova sobre o abastecimento de água e qualidade do serviço}

As entrevistas realizadas com os moradores do bairro negro Rua Nova permitiram elucidar que a perspectiva da água naquele território se traduz como uma concepção mais mercadológica, pois eles acabavam pagando pela água quando abastecidos por carro-pipa, tendo o seu direito à água violado, uma vez que o Estado deveria garantir 0 acesso à água para consumo humano. Um setor que também lucra com a falta de abastecimento pela rede pública de distribuição de água é o das empresas que produzem e comercializam água envasada, pois a população acaba gastando mais com essa aquisição.

Segundo os entrevistados, por um longo tempo os moradores enfrentaram a falta ou precariedade no abastecimento público de água no bairro, o que pode ter resultado em um número significativo de pessoas, a maioria

negros não conseguindo o êxito esse movimento ficou conhecido como Revolta dos Malês. $<$ http://smec.salvador.ba.gov.br/documentos/arevolta-dos-males.pdf>. Autor: João José Reis, A Revolta dos Malês em 1835. 
crianças, acometidas com doenças relacionadas à água. As famílias ali residentes eram abastecidas por meio de fontes alternativas como chafarizes, carros-pipa e bicas, sendo os chafarizes a mais utilizada para o suprimento das necessidades delas. As lutas empreendidas pela população e pela
Associação de Moradores da Rua Nova (Amorun), em defesa de seus direitos, conduziram a conquista de diversos serviços públicos, inclusive os de abastecimento de água e de esgotamento sanitário, porém o acesso a esses serviços públicos não significa equidade na qualidade de sua prestação.

Tabela 1- Rendimento domiciliar mensal (em salários mínimos) segundo raça/cor, de pessoas de 10 anos ou mais de idade residentes no bairro Rua Nova

\begin{tabular}{c|c|c|c|c|c|c}
\hline Salários Mínimos & Total & Branca & Preta & Parda & Amarela & Indígena \\
\hline Total & $100,00 \%$ & $11,09 \%$ & $31,50 \%$ & $56,65 \%$ & $0,68 \%$ & $0,08 \%$ \\
\hline Até 1/4 & $3,64 \%$ & $0,32 \%$ & $1,37 \%$ & $1,95 \%$ & & \\
\hline Mais de 1/4 a 1/2 & $5,34 \%$ & $0,48 \%$ & $1,86 \%$ & $2,97 \%$ & $0,03 \%$ & \\
\hline Mais de 1/2 a 1 & $30,79 \%$ & $3,39 \%$ & $10,01 \%$ & $17,13 \%$ & $0,22 \%$ & $0,04 \%$ \\
\hline Mais de 1 a 2 & $12,34 \%$ & $1,75 \%$ & $3,96 \%$ & $6,52 \%$ & $0,10 \%$ & $0,01 \%$ \\
\hline Mais de 2 a 3 & $1,70 \%$ & $0,25 \%$ & $0,51 \%$ & $0,93 \%$ & $0,01 \%$ & \\
\hline Mais de 3 a 5 & $1,13 \%$ & $0,23 \%$ & $0,28 \%$ & $0,60 \%$ & $0,02 \%$ & \\
\hline Mais de 5 a 10 & $0,30 \%$ & $0,06 \%$ & $0,09 \%$ & $0,15 \%$ & & \\
\hline Mais de 10 a 15 & $0,01 \%$ & & & $0,01 \%$ & & \\
\hline Mais de 15 a 20 & $0,02 \%$ & & & $0,02 \%$ & & \\
\hline Mais de 20 a 30 & $0,01 \%$ & & & $0,01 \%$ & & \\
\hline Mais de 30 & & & & & & \\
\hline Sem rendimento & $44,72 \%$ & $4,61 \%$ & $13,42 \%$ & $26,36 \%$ & $0,30 \%$ & $0,03 \%$ \\
\hline
\end{tabular}

Fonte: IBGE (thiago.ambientalista@gmail.com, 2020).

Tabela 2 - Dados relativos ao abastecimento de água, segundo raça/cor. Bairro Rua Nova, Feira de Santana-Bahia, 2010. $\mathrm{N}=13.073$

\begin{tabular}{|c|c|c|c|c|c|c|}
\hline & \multicolumn{6}{|c|}{ Tipos de abastecimento de água } \\
\hline & $\begin{array}{c}\text { Não } \\
\text { aplicável }\end{array}$ & $\begin{array}{l}\text { Rede geral de } \\
\text { distribuição }\end{array}$ & $\begin{array}{c}\text { Poço ou } \\
\text { nascente na } \\
\text { propriedade }\end{array}$ & $\begin{array}{c}\text { Poço ou nascente } \\
\text { fora da } \\
\text { propriedade }\end{array}$ & $\begin{array}{c}\text { Água da chuva } \\
\text { armazenada em } \\
\text { cisterna }\end{array}$ & Outra \\
\hline Branca & & $11,13 \%$ & $0,06 \%$ & $0,11 \%$ & & $0,20 \%$ \\
\hline Preta & & $29,34 \%$ & $0,07 \%$ & $0,17 \%$ & & $0,97 \%$ \\
\hline Parda & $0,05 \%$ & $55,79 \%$ & $0,20 \%$ & $0,29 \%$ & & $0,89 \%$ \\
\hline Amarela & & $0,67 \%$ & & & & \\
\hline Indígena & & $0,06 \%$ & & & & \\
\hline Total & $0,05 \%$ & $96,99 \%$ & $0,33 \%$ & $0,57 \%$ & & $2,06 \%$ \\
\hline
\end{tabular}

Fonte: IBGE (thiago.ambientalista@gmail.com, 2020).

Enquanto isso, segundo os entrevistados, no centro da Cidade e nos bairros vizinhos Kalilândia e Capuchinhos, bairros de população com maior poder aquisitivo, já contavam com melhores serviços públicos de água e esgoto, ou seja, dispunham de rede de distribuição de água e rede coletora de esgoto sanitários, possibilitando à população residente melhores condições de qualidade de vida e bem-estar que à da população do bairro Rua Nova. No 
mesmo sentido da narrativa anterior, a entrevista com o Sr. João, morador do bairro Rua Nova, apresenta apontamentos que elucidam como as políticas públicas em Feira de Santana historicamente direcionaram suas ações para o benefício aos grupos hegemônicos:

(...) no centro da Cidade já tinha, tudo foi feito primeiro no Centro, Getúlio Vargas que era o bairro da alta elite, sempre foi da alta elite. Av. Getúlio Vargas e aquele trecho da Rodoviária, e, também, muitas vezes ia para as fazendas porque era prioridade (João, 22/01/2020).

A narrativa acima acrescenta também a este estudo como a cidade de Feira de Santana legitimou a sua urbanização a partir do centro urbano ocupado em sua maioria pela população de maior poder aquisitivo. O foco da urbanização, precisamente na sede do Município em estudo, se configura devido a funcionalidade histórica da Cidade, a qual inicialmente teve o seu despontar econômico ocasionado por uma feira livre que se instalara em uma região que com o passar das décadas se tornou uma das maiores vias de circulação e moradia da burguesia e políticos da Cidade, recebendo o nome de Av. Getúlio Vargas (MACHADO, 1965, apud MIRANDA, 2014).

Por isso, a correlação entre raça e classe social é muito evidente na urbanização e disponibilidade de serviços públicos de água e esgoto na sede municipal de Feira de Santana a partir da década de 1950 quando dá início a urbanização, segundo a obra de Oliveira (2014). Visto que o ato de urbanizar demanda uma articulação que envolve políticas públicas e, consequentemente, recursos financeiros, ambas as ações empreendidas por homens brancos, o poder hegemônico, que desenham as cidades e reforçam os territórios próprios das elites e os espaços destinados aos grupos subalternizados.

Essa experiência vivenciada pelos entrevistados é a realidade ainda hoje das populações de baixa renda e negras no Brasil. Tal fato expõe parte da sociedade que tem seu usufruto de direitos humanos restringidos por viverem sem prestação adequada dos serviços públicos de saneamento básico. Para Nahas et al. (2019, p.12) “(...) nas áreas de privação socioeconômica mais elevada se concentram a falta de investimento em infraestrutura de saneamento". Os autores destacam ainda:

(...) domicílios com responsáveis com "pele branca" apresentavam uma chance mais elevada em $32 \%$ de ter acesso adequado ao abastecimento de água e em 39\% de ter acesso ao esgotamento sanitário, quando comparados com domicílios com chefes de pele "não branca". Tal diferença se agrava porque, na Região Metropolitana de Belo Horizonte, 60\% dos chefes de domicílio são da categoria "pele não branca" (cor da pele preta, parda, indígena ou amarela) (NAHAS et al., 2019, p.13).

O contexto apresentado por Nahas et al. (2019) diz muito do bairro negro Rua Nova, mesmo diante de um cenário apresentado pelo IBGE (2010) com quase 100\% (96,99\%) de domicílios ligados a rede pública de abastecimento de água, a qualidade de acesso a esse serviço público de saneamento básico é desigual. $\mathrm{Na}$ entrevista realizada com o $\mathrm{Sr}$. João, as lutas da Associação em busca de melhores condições de saúde e qualidade de vida são explicitadas em sua fala:

A Associação de Moradores sempre foi reivindicativa aqui, as pessoas se reuniam para cobrar mesmo, inclusive o atendimento médico (...) Só que só vieram tomar providência a partir dos anos 80, que vieram e fizeram a UBS e depois da UBS já passou para a Policlínica, mas tinha tudo isso (João, 22/01/2020).

Nesse aspecto sugere-se que a Associação de Moradores tem desempenhado um papel significativo para exigir dos diferentes governos ao longo do tempo, o atendimento adequado à saúde, o que também inclui a rede pública de distribuição de água e a rede coletora de esgotos sanitários no bairro Rua Nova como citado pelo entrevistado Sr. João:

(...) não foi feito todas as ruas logo, ela foi feita e teve umas ruas que ficou muito tempo sem ter, depois que se cobrando nas reuniões que a gente fazia na comunidade, a gente cobrava para que toda a população viesse a ser atendida, isso sempre teve no passado (João, 22/01/2020). 
A fala do entrevistado apresenta as prioridades dentro daquela localidade por parte do poder público municipal e a empresa prestadora dos serviços em implantar e operar a rede de distribuição de água e a rede coletora de esgotos sanitários.

Nesse sentido, o Sr. José evidencia o que foi dito pelo Sr. João ao relatar o seguinte:

Aí tudo já tinha (rede de água e esgoto), Jardim Cruzeiro já tinha, Rua Nova já tinha, essa parte de cima aí tinha, dessa parte daqui, daquela esquina ali para baixo que não tinha (...) aqui é o limite do Jardim Cruzeiro com Rua Nova (José, 03/02/2020).

$\mathrm{Na}$ fala do Sr. José aparece um outro bairro, Jardim Cruzeiro, o qual ele aponta como uma localidade com todas as ruas com rede pública de distribuição de água e com esgotamento sanitário. Geograficamente, o bairro Rua Nova faz divisa com o bairro Jardim Cruzeiro. Acerca da composição racial do Jardim Cruzeiro, em uma pesquisa sobre violência, Silva et al. (2012) apontam que este bairro possui a maior parte da sua população não negra e com baixo índice de agressões físicas. Apresentar este dado é relevante para destacar que mais uma vez está em construção uma argumentação que estabelece um viés sobre o descaso das políticas públicas de água e esgoto para o bairro negro em estudo.

Em outro momento desta investigação, se destaca outros bairros de Feira de Santana, com predominância de população branca, com acesso universal ao abastecimento público de água e distribuição regular. Sobre isto, o Sr. João, um antigo morador do bairro Rua Nova traz em sua memória no dia da entrevista a visão das pessoas em relação àquela rua: "esta área as pessoas percebiam como mais marginalizada, e era a rua mais excluída, sendo assim, os serviços demoravam mais tempo para serem instalados" (João, 22/01/2020).

Segundo IBGE (2010), o bairro Rua Nova mesmo tendo já superado a fase que faltava o abastecimento de água, conta com 96,99\% da população com acesso à rede geral de distribuição de água, que, para a Sra. Helena, desperta um sentimento de privilégio, devido à sua percepção de nesse momento não precisar gastar tempo em ir buscar água já que não ocorre mais a intermitência do serviço, segundo ela: "Aqui é um bairro privilegiado (...) você dificilmente vê dizer que faltou água na Rua Nova, é raridade" (Helena, 26/11/2019).

Portanto, essa percepção da Sra. Helena acerca da qualidade do serviço prestado à população negra do Bairro é divergente em relação a um recente episódio vivenciado pelo Sr. José. Dois meses antes da realização dessa entrevista, com os dois entrevistados inseridos no mesmo território pesquisado, mas em áreas diferentes do Bairro, pode-se identificar a atitude da empresa pública de água e esgoto. Segue o relato de Sr. José:

Quando a Embasa inventa de cortar a água da gente aqui, cortar nada ela desliga mesmo, que ela nem diz que dia é que vai faltar, desliga e acabou (...) foi quase 30 dias que ficou sem água aqui, a gente ficou ligando para lá, reclamando, todo mundo reclamando aí oh, só faltou água da esquina dali até a esquina de cá de baixo, esse trecho aqui (José, 03/02/2020).

As reclamações feitas pelos moradores por telefone à Embasa perduraram por 30 dias, tendo recebido a mesma resposta por todo esse tempo no qual dizia: "uma bomba para abastecimento estava quebrada e a manutenção já estava sendo realizada", porém a solução do problema não acontecia. Sendo assim, depois de bastante insistência, um técnico da Empresa esteve in loco para tentar verificar a razão do problema. Depois de o funcionário verificar os equipamentos do sistema de distribuição de água para aquela área, surge a sua informação: "foi porque consertaram e esqueceram de abrir a transmissão (o registro)" (José, 03/02/2020).

A negligência por uma postura emergente frente aos fatos informados pelos entrevistados por parte da empresa prestadora do serviço público pode ser revelada como um ato de discriminação aos moradores usuários que pagam pelo serviço. Para Almeida (2018) a discriminação de fato é um processo em que a situação específica de grupos minoritários é ignorada, e a consequência das práticas de discriminação ao longo do tempo leva à estratificação social, um fenômeno intergeracional, pois os percursos da vida de todos os membros de um grupo social, incluindo as chances de ascensão social, de reconhecimento e de sustento material, são afetados. 
Essa colocação feita por Sílvio Almeida (2018) remete muito a realidade vivida por Carolina Maria de Jesus $^{2}$ (2014) na favela que morava na cidade de São Paulo às margens do rio Tietê. Carolina Maria de Jesus e os demais moradores não tinham água encanada em casa, precisavam sair para buscar água no chafariz público que existia em sua comunidade. Todos pagavam uma tarifa pela água que os abastecia. Certo dia não havia água no chafariz, e então a saída foi pegar água na casa da vizinha, que Carolina Maria de Jesus considerou como uma casa de alvenaria, casa essa que estava fora do seu contexto de urbanismo, porque ali não faltava água, os moradores não precisavam se deslocar para pegar água, o esgoto não passava na porta de casa, e a porta de sua casa não era lugar de despejo de resíduos domiciliares, uma realidade contrária vivida pela maioria das famílias que moravam na comunidade em casas de madeira aproveitada/tapume.

Nesse contexto, Therborn (2010) também apresenta atitudes sutis como a tomada pela empresa pública de abastecimento de água. Ele revela como a discriminação a grupos étnico-raciais, de mulheres, de pobres e de comunidades rurais contribui para a existência de distanciamentos, pois leva ao caminho do aumento da desigualdade. Ou seja, as populações negras, quilombolas, indígenas, ribeirinhas em geral são economicamente de baixa renda, com isso, os acessos à bens de consumo por esses povos se tornam mais difíceis, promovendo o distanciamento entre quem tem e que não tem.

Diante desses argumentos é possível apresentar o que de fato acontece quando a população do bairro negro Rua Nova de Feira de Santana é atingida pelo descaso do abastecimento de água. A Sra. Helena recorda bastante dessa época sendo ainda uma criança entre 6 a 8 anos de idade em que junto com sua mãe iam buscar água no chafariz. A sua narrativa revela que a atividade de ir buscar água no chafariz foi feito por mulheres, muitas chegavam a dormir na fila para conseguir encher as latas que eram colocadas na cabeça no deslocamento até a residência. Essa é a realidade vivida desde o período colonial por homens negros e mulheres negras, que, livres ou cativos, realizavam a prática de abastecer a Casa Grande com potes de água (REZENDE; HELLER, 2008).

As experiências vividas pelos moradores do bairro Rua Nova mostram o que foi dito anteriormente, sendo que a Sra. Ana traduz isso em sua fala quando houve falta de água na área em que mora, por meio de seu relato: “(...) faltou (água) foi quando o povo ficou tudo doido aí. Pegaram água aqui, que a cisterna ficou lá embaixo, pouquinho assim (Ana, 05/02/2020)." O Sr. José, também morador do bairro Rua Nova, da mesma área da Sra. Ana, relata que quando falta água da rede de distribuição operada pela Embasa a solução é a água da bica, como segue:

Era ali oh (aponta para a bica)! A solução da gente era água mineral, tive que comprar seis vasos de água mineral para ficar bebendo água. É! Olha lá, não é mentira não, se você entrar ali eu já tenho quatro ali no hall ali, porque de tanto que já tinha comprado mesmo, agora já compro em grande quantidade e deixo estocado, porque não sei quando vai faltar água, entendeu? E ali só presta para tomar banho, e olhe lá tomar banho, e lavar roupa, essas coisas mais nada, e beber não presta, cozinhar e beber tem que comprar água mineral se não tiver dinheiro fica com fome e com sede, se não, já era (José, 03/02/2020).

A fala do Sr. José evidencia certa indignação na prestação do serviço público de abastecimento de água por ter que investir na compra de água envasada para suprir a demanda do consumo na sua residência e ainda conduz a refletir sobre quem não tem recursos financeiros para adquirir água envasada, pois esta parcela de famílias poderá ficar com sede e com fome. Para ele deve haver uma preocupação com a água da solução alternativa porque não é segura para ser consumida para ingestão e para o preparo de alimentos; e mesmo assim, tem pessoas naquele espaço que a tem como opção única para suprimento quando de sua necessidade/precisão.

\footnotetext{
2 Autora de diversos livros, dentre eles "Quarto de Despejo".
} 
Diante disso, tal relato sugere uma diferenciação no atendimento ao acesso à esses serviços públicos nessa determinada área do bairro Rua Nova que contempla poucas ruas sendo essas limítrofes ao bairro vizinho.

O Sr. José, ao ser questionado sobre a atitude da Embasa, faz o seguinte comentário: "Rapaz, a atitude dela é a mais precária possível que existe aqui na área, isso não é só a gente não a Rua Nova toda é assim (José, 03/02/2020). A fala da Sra. Helena complementa: "a gente sente que liga para a Embasa e não tem muita atenção, eles limpam depois. Passa um tempo, mas depois vem, de imediato não vem. (...) aqui é periferia, eles consideram como periferia. Só na hora de cobrar que somos do Centro, aí eles têm essa dificuldade maior (Helena, 25/11/2019). Ainda sobre as queixas da Embasa, a Sra. Maria expõe sua visão: "Oh, pelo que eu vejo que mesmo que a gente ligue para a Embasa quando o serviço é em prol da Empresa é rápido. Por exemplo: se é um corte, é rápido, se é uma ligação, é rápido, mas quando a gente vê assim verificações de vazamento, poxa custa vir, eles demoram, quando vem eles abrem um buraco em qualquer lugar e fica por meses, dias, incomodando aquelas pessoas" (Maria, 25/11/2019).

A manutenção desse comportamento da empresa pública cria na população um sentimento de que eles não merecem um serviço público de qualidade que tenha como objetivo garantir o bem-estar de todos, e por muitas vezes a solução pretendida se concretiza após diversos episódios de reclamações e reivindicações, enquanto deveria ocorrer de imediato. E por meio da análise de suas falas, é possível verificar a percepção que os moradores do bairro negro Rua Nova possuem quando a Embasa oferece uma qualidade de serviço superior aos bairros onde reside a elite, a população de maior renda mensal e maior capacidade de pagar as tarifas cobradas.

No tocante, as condições e características expostas ao bairro negro Rua Nova, isso se caracteriza como racismo conforme Almeida (2018), pois mais uma vez permite a conformação da extrema violência exercida à população de um bairro pobre e majoritariamente negro, chega a ser a naturalização em conviver em áreas sem condições adequadas de saneamento básico, sem saúde, sobretudo podendo levar à morte tanto crianças como pessoas idosas em estado de vulnerabilidade.

A percepção da Sra. Helena sobre a Embasa e a Prefeitura é que não dão atenção ao bairro Rua Nova, pois não é prioridade atender a essa região porque é considerada periferia. Nesse sentido, a Sra. Maria acredita que tal comportamento retrata o racismo velado utilizado pelas instituições públicas seguido pelo racismo estrutural que atravessa esses corpos de modo que não percebem os danos que atingem a população da qual também fazem parte.

Nesse sentido, Almeida (2018) considera que de fato as instituições atuam na formulação de normas e imposição a padrões sociais que atribuem privilégios aos brancos ou a grupos raciais específicos. Exemplo disso é a exigência por locais planos, regulares, com vias de acesso sem grandes empecilhos, com regularização fundiária para que as famílias pobres e negras, periféricas, do subúrbio, tenham direito à água com qualidade e quantidade suficiente para seu consumo e ao esgotamento sanitário, enquanto a população negra, tem como os lugares destinados a elas por meio de política do Estado, os morros e as áreas mais distantes dos centros urbanos. Assim, atuar nessas áreas para as empresas prestadoras de serviços é um fator gerador de custos e sendo a população residente de baixa renda o valor investido não tem o retorno financeiro esperado nas tarifas, nos preços cobrados.

Almeida (2018) aponta ainda que o racismo institucional está vinculado a uma ordem social em que faz parte de uma estrutura que privilegia determinados grupos sociais e, não é algo criado pela instituição, mas reproduzido, porque a sociedade é racista e a estrutura social é constituída de conflitos de classe, raça e gênero. A questão também de os trabalhadores da Empresa poderem ter interesse em alcançar posições melhores por uma ação que beneficie uma pequena parcela da população sugere a manutenção ativa de problemas de desigualdade racial no saneamento básico. Enquanto as instituições da área não promoverem soluções para tais problemas elas tenderão a continuar a 
reproduzir práticas racistas já tidas como normais na sociedade.

\section{CONCLUSÃO}

Diante do exposto é possível concluir que o objetivo da pesquisa que deu origem a esse artigo foi alcançado, ao evidenciar as desigualdades raciais e revelar a percepção dos moradores quanto às atitudes tomadas pela empresa pública no bairro negro Rua Nova de Feira de Santana, fazem parte do que se tem como referência dentro da discussão do racismo estrutural, bem como institucional, porque em relação ao atendimento com serviço público de abastecimento de água, deve-se prestar um serviço de qualidade, de forma contínua e segura e à custo módico a todos sem distinção de cor e classe social.

Passados os séculos, a Casa Grande não mais existe, entretanto os detentores do capital seguem desfrutando do direito, que deveria ser garantido para todos, de abastecimento de água regular, com qualidade e quantidade suficiente para seu uso, enquanto, populações pobres, em geral negras, têm seus direitos básicos e essenciais violados pelas instituições públicas, sendo ainda possível nos dias de hoje, ver mulheres negras ocupando seu tempo para buscar água nos lugares distantes de casa, sendo que esse tempo poderia ter sido utilizado para seu próprio desenvolvimento, para a sua formação, ou em atividade laboral não domiciliar que proporciona geração de renda.

O racismo estrutural praticado pelas instituições, tanto o titular dos serviços como os prestadores, é parte de uma ordem social, nesse caso, e assim, a instituição só reproduz o que é praticado também enquanto sujeitos únicos. As populações negras e pobres precisam ser vistas como qualquer outro povo, a cor da pele e a classe social não podem definir normas e padrões designados por grupos hegemônicos nas instituições públicas sem ouvir as suas demandas.

A área da Engenharia Sanitária e Ambiental precisa humanizar seus trabalhos tecnico-científicos, porque na grande maioria das vezes não leva em conta a relação humana com as pessoas onde projeta, implanta e opera as intervenções técnicas, as tecnologias para atendimento dos moradores. As populações que carecem dos serviços desses profissionais precisam de algum modo ser ouvidas, sobretudo, atendidas, conforme a realidade delas.

O racismo como tecnologia do poder é capaz de levar crianças e idosos à morte pela via da política de ausência dos serviços públicos de saneamento básico, sobretudo violar o direito humano essencial à água e ao esgotamento sanitário aprovado e declarado pela Assembleia Geral das Nações Unidas, em 28/07/2010 (UN, 2010), e, também, não atender ao princípio da universalização do acesso a esses serviços.

É importante que pessoas negras também ocupem esses espaços de poder na busca pela equidade e igualdade onde todos sejam contemplados por serviços públicos de saneamento básico de qualidade e a preços módicos. A representatividade é importante para as lutas antirracistas, e para o enfrentamento dos atos discriminatórios contra pessoas negras, podendo tornar efetivo o desmantelar das narrativas discriminatórias à população negra, dos que moram em áreas ocupadas e que nessa condição não teriam direito à água.

Vale aqui destacar a importância dessa pesquisa para a área de saneamento básico que discute políticas públicas, de forma a demarcar a necessidade da formulação, sobretudo na implementação de políticas públicas de saneamento básico capazes de atender às necessidades específicas da população dos bairros negros de Feira de Santana, da Bahia e do Brasil. As reparações históricas precisam acontecer; foram 300 anos de escravidão, e no pós-abolição ainda existem brasileiros que estão excluídos do acesso a direitos básicos como à água e ao esgotamento sanitário, à saúde, à educação, condição decorrente de uma política do Estado brasileiro que não buscou promover a reparação e a inclusão social desses sujeitos sociais.

\section{AGRADECIMENTO}

O primeiro autor agradece à Coordenação de Aperfeiçoamento de Pessoal de Nível Superior (CAPES) pelo apoio e bolsa de estudos concedida para a realização de seu mestrado. 


\section{REFERÊNCIAS}

ALEIXO, B.; REZENDE, S.; PENA, J. L.; ZAPATA, G.; HELLER, L. Direito Humano em perspectiva: desigualdades no acesso à água em uma comunidade rural no Nordeste brasileiro. Ambiente \& Sociedade. São Paulo, v. XIX, n. 1, p.63-82, jan./mar. 2016.

ALMEIDA, S. L. de. 0 que é Racismo Estrutural. Belo Horizonte-MG: Ed. Letramento, 2018.

BAEZ, N. L. X. A construção histórica das ações afirmativas para afrodescendentes no Brasil. Revista Brasileira de Direito. Passo Fundo: v. 13, n. 3, p. 514-538, set.-dez./2017.

BORJA, P. C.; MORAES, L. R. S.; BOTEON, S. C. Águas, resíduos e lugares na cidade de Salvador. In: SANTOS, M. E. P. et al. QUALISalvador-Qualidade do Ambiente Urbano da Cidade da Bahia. Salvador: EDUFBA, 2021. p. 235-309.

BORJA, P. C.; FREDIANI, D. A.; BARRETO, T. B.; MORAES, L. R. S. Serviços públicos de saneamento básico em Salvador-BA: um estudo sobre as desigualdades de acesso. Revista Eletrônica de Gestão e Tecnologias Ambientais-GESTA, Salvador, v.3, n.2, p.140-152, 2015.

BRASIL. Constituição da República Federativa do Brasil. Brasília: Senado Federal, 1988.

Lei n. 11.445, de 05 de janeiro de 2007, que estabelece diretrizes nacionais para 0 saneamento básico e para a política nacional de saneamento básico. Brasília-DF, 2007.

Ministério das Cidades. Plano Nacional de Saneamento Básico (PLANSAB). Documento em revisão submetido à apreciação dos Conselhos Nacionais de Saúde, Recursos Hídricos e Meio Ambiente. Brasília-DF: Ministério de Desenvolvimento Regional/Secretaria Nacional de Saneamento, 2019.

Ministério do Desenvolvimento Regional. Sistema Nacional de Informação sobre Saneamento-SNIS. Índices de atendimento. Brasília-DF, 2020.

CUNHA JÚNIOR., H. Afrodescendência e espaço urbano. In: CUNHA JÚNIOR, H.; RAMOS, M. E. R. (Org.). Espaço urbano e afrodescendência: estudo da espacialidade negra urbana para o debate das políticas públicas. Fortaleza: Edições UFC, 2007. p.17-46.

Bairros negros: epistemologia dos

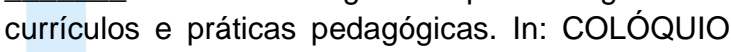

LUSO-AFROBRASILEIRO DE QUESTÕES CURRICULARES EDUCAÇÃO, FORMAÇÃO E CRIOULIDADE, III., 2017, Cidade da Praia. Anais... Cidade da Praia, Cabo Verde: UniCV, 2017.

FOUCAULT, M. Em defesa da sociedade. São Paulo: Editora Martins Fontes, 2005.

GARCIA, A. S. Desigualdades raciais e urbanas em Bangu: de senzala a vila operária, de vila operária a bairro/cidade negra. In: Espaço urbano e afrodescendência: estudo da espacialidade negra urbana para o debate das políticas públicas. CUNHA JÚNIOR, H.; RAMOS, M.E.R. (Org.). Fortaleza: Edições UFC, 2007.p. 17- 46.

GOMES, U. A. F.; HELLER, L. Saneamento Básico em Vilas e Favelas: qual o papel da regularização fundiária? Revista Ver a Cidade, Ano IV, n.5, p. 116, out. 2009.

IBGE 2019. Dados do Censo Demográfico de 2010 do bairro Rua Nova, Feira de Santana-BA [mensagem pessoal]. Mensagem recebida por <thiago.ambientalista@mail.com> em 28 fev. 2020.

IBGE. Instituto Brasileiro de Geografia e Estatística. IBGE Cidades - Panorama. Disponível em:<https://cidades.ibge.gov.br/brasil/ba/feira-desantana/panorama>. Acesso em: 22 mar. 2019.

IPEA. Instituto de Pesquisa Econômica Aplicada. Retrato das desigualdades de gênero e raça. Indicadores - Habitação e Saneamento. Brasília: Ipea, 2015. Disponível em: <https://www.ipea.gov.br/ retrato/indicadores_habitacao_saneamento.html>. Acesso em: 17 mai. 2021.

JESUS, V. de. Racializando um olhar (sociológico) da saúde ambiental em saneamento da população negra: um continuum colonial chamado de racismo ambiental. Saúde e Sociedade (online), v. 29, n 2, p. 1-15, 2020.

LARREA, C.K. et al. Epidemiologists working together with anthropologists: lessons from a study to evaluate the epidemiological impact of a city-wide sanitation program. Cad. Saúde Pública, Rio de Janeiro, v. 29, n. 3, p. 461-474, mar. 2013. Disponível em: https://www.scielosp.org/article/csp/ 2013.v29n3/461-474/. Acesso em: 17 abr. 2021.

LIRA, J. T. C. O Urbanismo e o Seu Outro: Raça, Cultura e Cidade no Brasil (1920-1945). Revista de Estudos Urbanos e Regionais/ANPUR, n.1, p.4778, mai. 1999.

MACIEL. A. C. et al. Responsabilidade Social: avaliação dos indicadores de estrutura física e serviços públicos pelos líderes comunitários de 
Marau-RS. RAIMED - Revista de Administração IMED, v.3, n.2, p. 132-145, 2013.

MARICATO, E. Metrópole na periferia do capitalismo: ilegalidade, desigualdade e violência. In: GONÇALVES. M. F. (Org). O novo Brasil. 1. ed. Porto Alegre: Editora Mercado Aberto, 1995. p. 261289.

MARQUES, E. C. From hygiene to the building of a city: the State and sanitation in Rio de Janeiro. História, Ciências, Saúde - Manguinhos, v. II, n. 2, p. 51-67, jun.-out. 1995.

MINAYO, M. C. de S. O desafio do conhecimento: pesquisa qualitativa em saúde. 3. ed. São Paulo: Hucitec/Abrasco 1994.

Ciência, técnica e arte: o desafio da pesquisa social. In: MINAYO, M. C. S. et al. (Orgs.). Pesquisa Social: Teoria, método e criatividade. Petrópolis: Vozes, 2004, p. 9-29.

Análise qualitativa: teoria, passos e fidedignidade. Ciências \& Saúde Coletiva, v. 17, n. 3, p. 621-626, 2012.

MIRANDA, E. O. "O negro quando sai da Rua Nova ele traz na cinta uma cobra coral": os desenhos dos corpos-territórios evidenciados pelo Afoxé Pomba de Malê. 2014. 168f. Dissertação (Mestrado em Desenho, Cultura e Interatividade) - Universidade Estadual de Feira de Santana, Feira de Santana, 2014.

NAHAS, M. I. P.; MOURA, A. S. A. de; CARVALHO, R. C. de; HELLER, L. Desigualdade e discriminação no acesso à água e ao esgotamento sanitário na região metropolitana de Belo Horizonte, Minas Gerais, Brasil. Cadernos de Saúde Pública. v. 35, n. 4, p.1-17, 2019.

OLIVEIRA, M. L. S. Feira de Santana no contexto da urbanização brasileira e a questão de moradia na favela. Feira de Santana: UEFS Editora, 2014.

PEREIRA, P. R. M. JUNIOR, V. C. RODRIGUES, Z. M. R. Desigualdade intraurbana dos indicadores de saneamento em São Luís-MA. In: JORNADA INTERNACIONAL DE POLÍTICAS PÚBLICAS, VI, 2013, São Luís-MA. Anais... São Luís: UFMA, 2013.

RAMOS, M. E. R. Bairros negros: uma lacuna nos estudos urbanísticos. Um estudo empíricoconceitual no bairro Engenho Velho da Federação, Salvador-BA. 2013. 283 f. Tese (Doutorado em Arquitetura e Urbanismo) - Faculdade de Arquitetura, Universidade Federal da Bahia, Salvador, 2013.

REZENDE, S; HELLER, L. A formação da sociedade brasileira e a realização de ações sanitárias: Brasil colônia e primeira metade do império (século XVI até meados do século XIX). In: 0 saneamento no Brasil: políticas e interfaces. Belo Horizonte-MG: Editora UFMG, p. 83-113, 2008.

SANTOS, M. E. P. et al. QUALISalvador-Qualidade do Ambiente Urbano da Cidade da Bahia. Salvador: EDUFBA, 2021.

SILVA, M. A. S.; LACERDA, R. dos S.; ARAÚJO, E. $M$. de. Vulnerabilidade e violência em Feira de Santana (BA). In: ENCONTRO DE VIOLÊNCIA INTRAFAMILIAR, III, 2012, Feira de Santana. Anais... Feira de Santana: UEFS, 2012, v. 2, p. 78 79.

THERBORN, G. Os campos de extermínio da desigualdade. Tradução da Revista Soundings, 2009, n.2, Novos Estudos-CEPRAP, 87, p.145156, 2010.

United Nations-UN. Resolution A/HRC/RES/15/9. Human rights and access to safe drinking water and sanitation. United Nations General Assembly, 2010. Disponível em: https://undocs.org/en/A/HRC/RES/15/9. Acesso em: 13 mai. 2020.

VALLADARES, L. A gênese da favela carioca - A produção anterior às ciências sociais. Revista Brasileira de Ciências Sociais. v. 15, n. 44, p. 5-34, out. 2000. 